\section{ISONIAZID AND WEIGHT GAIN} A PILOT INVESTIGATION

\author{
BY
}

I. S. MUDIE, M.B., D.T.M.\&H.

N. W. HORNE, M.B., M.R.C.P.Ed.

AND

J. W. CROFTON, M.D., F.R.C.P.

(From the Department of Tuberculosis and Diseases of the Chest, University of Edinburgh)

In groups of patients with pulmonary tuberculosis treated with isoniazid a remarkable gain in weight has been one of the principal effects reported (Medical Research Council, 1952, 1953). Compared with other treatments, weight gain has been so marked as to lead to a suspicion that a non-specific effect on metabolism was involved as well as a direct effect on the disease. There have also been reports of a great increase in appetite, undue sleepiness or wakefulness, and alterations in emotional tone, although none of these has been so frequent as the gain in weight. In order to determine whether it was worth while undertaking detailed metabolic investigations or a large-scale trial in normal subjects it was decided to carry out a controlled pilot trial on a small scale.

\section{Methods}

The subjects were eight male medical members of this department aged between 25 and 40 . None had had tuberculosis, and in all a normal radiograph of the chest was obtained immediately before the start of the trial. They were divided by random allocation into a treatment group and a control group, each of four subjects. No subject knew to which group he had been allotted. The total period of the trial was fourteen weeks, including an initial observation period of two weeks before administration of any drugs and a final two-weeks period after administration had stopped. The control group received capsules containing lactose, and the treatment group was given isoniazid $100 \mathrm{mg}$. twice a day in identical capsules. The control group received lactose for the whole ten weeks. During the ten weeks of administration the treatment group received isoniazid for eight weeks and lactose for two weeks. By this plan each subject given isoniazid had control periods on lactose and on observation alone. In addition the whole treated group was compared with a control group, randomly selected, which received only lactose.

The subjects were weighed_weekly to the nearest quarterpound $(0.1 \mathrm{~kg}$.). In order to avoid suggestion or alteration in food intake they were weighed with their backs to the scale and were not informed of the readings. At the end of every week's treatment each subject filled in a questionary recording his impressions with regard to appetite, sleep, emotional tone, or any other possible effects of the drug.

\section{Results}

The weight changes are given in the Table. The individual gains or losses of weight over the two-weeks initial and two-weeks final observation periods are listed for both treatment and control groups. For the control group the weight change over the ten weeks on lactose is recorded, but for the treated group the changes during the two weeks on lactose and the eight weeks on isoniazid are given separately. The average weight change per man per week is calculated for each period. It will be seen that the average weight gain per man per week when the treated subjects were on isoniazid was $0.13 \mathrm{lb}$. $(59 \mathrm{~g}$.), compared with $0.12 \mathrm{lb}$. $(54 \mathrm{~g}$.) when on lactose and $0.53 \mathrm{lb}$. (240 g.)
Weight Changes in Normal Males Given Isoniazid and in a Control Group

\begin{tabular}{|c|c|c|c|c|c|c|c|}
\hline & & & \multicolumn{5}{|c|}{ Loss or Gain in Weight (lb.) } \\
\hline \multicolumn{3}{|c|}{ Subject } & $\begin{array}{c}2 \text { Weeks' } \\
\text { Initial } \\
\text { Observa- } \\
\text { tion }\end{array}$ & $\begin{array}{l}2 \\
\text { Weeks } \\
\text { on } \\
\text { Lactose }\end{array}$ & $\begin{array}{c}8 \text { Weeks } \\
\text { on } \\
\text { Iso- } \\
\text { niazid }\end{array}$ & $\begin{array}{l}2 \text { Weeks' } \\
\text { Final } \\
\text { Observa- } \\
\text { tion }\end{array}$ & $\begin{array}{c}\text { Net } \\
\text { Change } \\
\text { in } \\
4 \text { Weeks }\end{array}$ \\
\hline $\begin{array}{c}\text { Treatment } \\
\text { T1 } \\
\text { T2* } \\
\text { T3 } \\
\text { T4 } \ldots \\
\end{array}$ & $\begin{array}{l}\text { rou } \\
\cdots \\
\cdots \\
\cdots \\
\cdots\end{array}$ & $\begin{array}{l}\cdots \\
\cdots \\
\cdots \\
\cdots\end{array}$ & $\begin{array}{l}+1 \\
+1 \frac{8}{1} \\
+1 \frac{1}{2} \\
0\end{array}$ & $\begin{array}{r}-\frac{1}{4} \\
+1 \\
+\frac{1}{2} \\
-\frac{1}{4}\end{array}$ & $\begin{array}{l}-3 \frac{1}{1} \\
+3 \frac{1}{2} \\
+4 \\
-4\end{array}$ & $\begin{array}{l}+1 \frac{1}{2} \\
-2 \\
+\frac{1}{2} \\
-1 \frac{1}{2}\end{array}$ & $\begin{array}{l}-1 \\
+41 \\
+6 \frac{1}{2} \\
-2\end{array}$ \\
\hline Total & . & . & +41 & +1 & +4 & $-1 \frac{1}{2}$ & $+7 \frac{8}{4}$ \\
\hline \multicolumn{3}{|c|}{\begin{tabular}{l}
\multicolumn{3}{c}{ Average weight change } \\
per man per week \\
(lb.) $\quad$..
\end{tabular}} & +0.53 & $+0 \cdot 12$ & $+0 \cdot 13$ & -0.17 & $+0 \cdot 14$ \\
\hline $\begin{array}{l}\text { Control gro } \\
\text { C1 } \\
\text { C2 } 2 \dagger \\
\text { C3 } \\
\text { C4 }\end{array}$ & $\begin{array}{l}\text { up: } \\
\therefore \\
\therefore \\
\therefore\end{array}$ & $\begin{array}{l}\cdots \\
\cdots \\
\cdots\end{array}$ & $\begin{array}{l}-1 \\
-1 \\
+24 \\
+1 \frac{1}{2}\end{array}$ & \multicolumn{2}{|c|}{$\begin{array}{c}10 \text { Weeks on Lactose } \\
+2 \frac{1}{4} \\
+6\end{array}$} & $\begin{array}{l}+5 \\
-1 \\
-1 \frac{1}{2} \\
0\end{array}$ & $\begin{array}{l}+64 \\
+4 \\
+14 \\
+28\end{array}$ \\
\hline Total & .. & . & $+1 \frac{1}{8}$ & \multicolumn{2}{|c|}{+10} & $+2 \frac{1}{2}$ & +144 \\
\hline \multicolumn{3}{|c|}{$\begin{array}{l}\text { Average weight change } \\
\text { per man per week } \\
\begin{array}{llr}\text { (lb.) } & \ldots & .\end{array}\end{array}$} & +0.22 & \multicolumn{2}{|c|}{$+0 \cdot 25$} & +0.36 & $+0 \cdot 26$ \\
\hline
\end{tabular}

* This subject stopped isoniazid after $6 \frac{1}{2}$ weeks because of Raynaud's phenomenon. The next weighing was at 7 weeks, so he is included in the calculations

+ Weight for final observation week not recorded: calculations based on a single final observation week and 13 weeks' total observation.

during the initial two-weeks observation period when no drug was administered. An average loss of $0.17 \mathrm{lb}$. $(77 \mathrm{~g}$.) occurred during the final two-weeks observation period, suggesting that there was no delayed effect of isoniazid in increasing weight. The control group averaged $0.25 \mathrm{lb}$. $(110 \mathrm{~g}$.) gain per man per week when on lactose and 0.22 $(100 \mathrm{~g}$.) and $0.36 \mathrm{lb}$. (160 g.) during the initial and final observation periods. The individual fluctuations in the two groups do not suggest that there was any difference between them attributable to the drug. It will be noted that both groups on average gained weight. This may be because the trial was started in January and continued to the early spring, or possibly because the trial itself had some psychological effect.

Appetite.-Of the four subjects in the control group, two noted no change; the other two recorded fluctuations at varying periods. In the treatment group, only one recorded an unchanged appetite; fluctuations occurred in the other three, but without any consistent pattern which suggested an effect of the drug.

Sleep.-In the control group two observed no change, whereas two recorded variations in their sleep requirements from week to week. They were the same subjects who had shown some variations in their appetite. In the treatment group three recorded no change, but the fourth said that he was definitely more sleepy in the evenings during the last three weeks of the course, and during the last two weeks had been having more frequent nightmares. It is, to say the least, doubtful whether these changes should be attributed to isoniazid.

Emotional Tone.-One of the control group stated that he had become more cheerful, but in the treatment group no changes were recorded.

Other Possible Side-effects.-The only other effect which might be of significance was an experience of one subject to whom isoniazid was being administered. After four and a half weeks of continuous isoniazid treatment he experienced Raynaud's phenomenon in both hands, with stiffness, blanching, and coldness. This became steadily worse during the ensuing two weeks, and the drug was stopped. There was steady improvement thereafter. This subject had never experienced Raynaud's phenomenon before, but its relation to isoniazid must remain in doubt. 


\section{Discussion}

The results of this study in man, although its scale was limited, are consistent with experiments in animals. Normal rats treated with isoniazid showed no significant gain in weight (Benson et al., 1952; Rubin et al., 1952), and in dogs there was no change in metabolic rate (Rubin and Burke, 1953). In man, Faloon (1953) found no change in nitrogen balance, appetite, or food intake in three patients with nontuberculous disease given isoniazid for six to eight days. The observations here presented provide no evidence that isoniazid has any effect in causing gain in weight in the normal human male. In view of the negative results, we do not contemplate engaging in a trial on a larger scale. It seems doubtful whether the minor side-effects noted above were attributable to isoniazid.

\section{Summary}

The average weekly weight gain in four healthy males receiving isoniazid for eight weeks was similar to the gain in the same group treated for two weeks with control capsules containing lactose and to the gain during four weeks on observation alone. The average weekly gain was less than that of a similar group of four males treated for 10 weeks with control capsules containing lactose. We have therefore obtained no evidence to suggest that isoniazid in tuberculous patients has an effect on weight gain other than that due to its effect on the disease. No side-effects were recorded which could be attributed with certainty to isoniazid. One member of the treated group became unduly sleepy; another experienced Raynaud's phenomenon for the first time. One of the control group experienced an unexpected increase in cheerfulness, but no change in emotional tone was recorded by any member of the treated group.

We are most grateful to our colleagues who cheerfully put up with the inconveniences of the trial. We also record our gratitude to Messrs. E. R. Squibb and Sons for a generous gift of the isoniazid and control capsules. This investigation is one of a series supported by a grant from the Royal Victoria Hospital Tuberculosis Trust.

REFERENCES

Benson, W. M., Stefko, P. L., and Roe, M. D. (1952), Amer. Rev. Tuberc. $65,376$.

Faloon, W. W. (1953). Ibid., 68, 207.

Medical Research Council (1952). British Medical Journal, 2, 735.

- (1953). Ibid., 1, 521

Rubin, B., and Burke, J. C. (1953). Amer. Rev. Tuberc., 67. 644

- Hassert, G. L., jun., Thomas, B. G. H., and Burke, J. C. (1952) Ibid., 65, 392 .

The annual report of the Fountain Hospital, the 600 bedded hospital at Tooting Grove for mentally defective children from London and Surrey, draws attention to Section 3 of the Mental Deficiency Act, which allows a child to be placed in hospital by the parents without the need of a magistrate's order. Of the 84 certified direct admissions to the Fountain Hospital during 1953 , over $80 \%$ were admitted under this procedure. The admission of young children without any legal formalities, the report continues, would go a long way towards improving the public's attitude to mental deficiency in young children. Indeed, a plea is made that this should be tried out experimentally. "If the Fountain Hospital, owing to its special circumstances, could be exempted for a temporary period from the normal working of the Mental Deficiency Acts experience would be gained in the voluntary care of defective children, comparable to that made possible by the Mental Treatment Act of 1930. This evidence might be of considerable value to the Royal Commission inquiring into the certification and detention of mental patients."

\section{BLOOD GROUPS AND GYNAECOLOGICAL CANCER}

\author{
BY
}

ERIK KROKFORS, Med.lic.

AND

OLAVI KINNUNEN

Lecturer in Gynaecology, Assistant Physician-in-Chief (From the Women's Clinic I and II, Helsinki, Finland)

Stocks showed in 1950 that the standardized mortality of cancer of the stomach tended to be greater in northern than in southern towns in England. $\mathrm{He}$ assumed this to be connected with the fact that gastric cancer depends on an irritant. In an attempt to explain the variations in mortality, Aird, Bentall, and Roberts (1953) demonstrated that the frequency of blood group A was greater in patients suffering from gastric cancer than in the general population of the same locality. They collected their series from a number of hospitals in England and Scotland, using as controls an equal number of patients chosen at random from the same hospital or, where this was difficult, estimating an equal control number from the blood-group frequencies in large numbers of the local population. In most cases diagnosis was confirmed by a histological report; in only a few cases were the authors dependent on radiological findings or on the clinical picture alone.

Table I shows the results of Aird, Bentall, and Roberts. It indicates that in different parts of England and Scotland the frequency of blood group A was

TABLE I

\begin{tabular}{|c|c|c|c|c|c|c|c|c|}
\hline & \multicolumn{4}{|c|}{ Cancer Cases } & \multicolumn{4}{|c|}{ Controls } \\
\hline & $\mathbf{O}$ & $\mathbf{A}$ & B & AB & $\mathbf{O}$ & $\mathbf{A}$ & $\mathbf{B}$ & $\mathbf{A B}$ \\
\hline $\begin{array}{l}\text { Newcastle ( } 101 \text { cases) } \\
\text { Leeds }(217 \text { cases) } \\
\text { Manchester ( } 771 \text { cases) } \\
\text { Liverpool ( } 217 \text { ca es) } \\
\text { Birmingham ( } 100 \text { cases) }\end{array}$ & $\begin{array}{l}43 \cdot 6 \\
42.4 \\
44 \cdot 7 \\
39 \cdot 2 \\
37 \cdot 0 \\
\end{array}$ & $\begin{array}{l}43 \cdot 6 \\
47.9 \\
44 \cdot 5 \\
44.7 \\
57.0\end{array}$ & $\begin{array}{r}11.9 \\
7.4 \\
6.4 \\
12.4 \\
3.0\end{array}$ & $\begin{array}{l}1 \cdot 0 \\
2 \cdot 3 \\
3 \cdot 8 \\
3 \cdot 7 \\
3 \cdot 0\end{array}$ & $\begin{array}{l}52.5 \\
46.5 \\
52.1 \\
49.7 \\
49.6\end{array}$ & $\begin{array}{l}37 \cdot 4 \\
40 \cdot 3 \\
38 \cdot 4 \\
39 \cdot 6 \\
44 \cdot 4 \\
\end{array}$ & $\begin{array}{l}7 \cdot 6 \\
7 \cdot 1 \\
7 \cdot 0 \\
7 \cdot 8 \\
3 \cdot 0\end{array}$ & $\begin{array}{l}2 \cdot 5 \\
6 \cdot 2 \\
2 \cdot 5 \\
2 \cdot 7 \\
3 \cdot 0\end{array}$ \\
\hline $\begin{array}{l}\text { Total of Northern } \\
\text { England }(1,406 \text { cases })\end{array}$ & $42 \cdot 9$ & $46 \cdot 4$ & $7 \cdot 6$ & $3 \cdot 1$ & $50 \cdot 7$ & $39 \cdot 3$ & $6 \cdot 8$ & $3 \cdot 2$ \\
\hline London $(1,340$ cases $)$ & $43 \cdot 1$ & $46 \cdot 0$ & $7 \cdot 9$ & $2 \cdot 9$ & $45 \cdot 8$ & $42 \cdot 2$ & 8.9 & $3 \cdot 1$ \\
\hline Scotland (478 cases) & $51 \cdot 2$ & $36 \cdot 4$ & $9 \cdot 6$ & $2 \cdot 7$ & $52 \cdot 6$ & $32 \cdot 5$ & $11 \cdot 7$ & $3 \cdot 1$ \\
\hline $\begin{array}{c}\text { Overall figures }(3,632) \\
\begin{array}{ccc} & (3,63 e s)\end{array}\end{array}$ & $44 \cdot 5$ & $44 \cdot 8$ & $7 \cdot 8$ & $2 \cdot 9$ & $48 \cdot 6$ & $39 \cdot 8$ & $8 \cdot 3$ & $3 \cdot 2$ \\
\hline
\end{tabular}

greater and that of blood group $O$ correspondingly less in patients with cancer of the stomach than in the general population.

\section{Our Own Investigations}

It seemed of interest to make a corresponding study of the distribution of the blood groups in patients suffering from gynaecological cancer. Our series consists of 300 patients with uterine or other gynaecological cancer whose blood groups had been determined; they were treated at the Women's Clinic of the University of Helsinki during the period 1948-53. Diagnosis was confirmed in all cases by a histological report. Owing to the centralization of hospital conditions in Finland, the majority of all cases of gynaecological carcinoma, both operative cases and those given radiation, are treated at the Women's Clinic in Helsinki. This being so, the patients no doubt represent a cross-section of the population as regards distribution of blood groups. The control series was therefore selected on a similar basis. 